\title{
A PERCEPÇÃO AMBIENTAL DOS JOVENS SOBRE A CIDADE DE MANAUS (AM)
}

José Cavalcante Lacerda Junior ${ }^{1}$

Resumo: O artigo objetiva apresentar a percepção ambiental dos jovens sobre a cidade de Manaus. Utiliza como estratégia metodológica uma entrevista semiestrutura e tece suas fundamentações teóricas no âmbito da relação pessoa-ambiente. Desse modo, os dados foram organizados a partir da Análise de Conteúdo e como resultado identificou a percepção dos jovens em torno da cidade diretamente conectada com o processo de apropriação. Tal conjuntura, demonstra que há um distanciamento e percepções de menor valência quando os jovens não se sentem integrados aos contextos, por outro lado, quando os jovens se sentem participativos a sua percepção vislumbra uma cidade a partir de uma potencialidade sustentável.

Palavras-chave: Percepção; Jovens; Cidade.

Abstract: The article aims to present the environmental perception of young people about the city of Manaus (AM, Brazil). It uses a semi-structured interview as a methodological strategy and weaves its theoretical foundations in the context of the person-environment relationship. Thus, the data were organized from Content Analysis and as a result identified the perception of young people around the city directly connected with the appropriation process. This situation demonstrates that there is a distance and perceptions of lesser value when young people do not feel integrated into the contexts, on the other hand, when young people feel participative, their perception glimpses a city based on sustainable potential.

Keywords: Perception; Young People; City.

\footnotetext{
${ }^{1}$ Instituto Federal do Amazonas - Ifam, Campus Manaus Distrito Industrial.

E-mail: jose.cavalcante@ifam.edu.br, Link para o Lattes: http://lattes.cnpq.br/4731128445071858
} 


\section{Introdução}

A relação pessoa-ambiente é um dos temas mais urgentes do século $\mathrm{XXI}$. A diversidade teórica que pulula essa interface, as diferentes estratégias metodológicas e a pluralidade de contextos que sustentam essa interação aglutinam, em comum, a preocupação com as crescentes problemáticas socioambientais. Entre os fios que tecem essa trama emergencial, encontra-se a relação dos jovens com a cidade. No mundo, e no Brasil, há uma significativa presença de jovens residindo nas cidades e inseridos em diversos contextos socioculturais que compõem um mosaico de interações urbanas.

Aliado a essa perspectiva, observa-se que as mobilizações e engajamentos ambientais, propagados e disseminados pela internet, principalmente pelas redes sociais, a partir dos jovens evidenciam a relevância dessa temática. O fenômeno mais explícito, nesse contexto, é o do movimento conduzido por Greta Thunberg, jovem sueca, que eclodiu em 2019. Na região amazônica, especificadamente na região metropolitana de Manaus, observa-se que, embora de maneira ainda embrionária, a constituição de coletivos de jovens em torno das questões ambientais e dos processos socioculturais (PAZ, 2017).

Nessa perspectiva, as cidades aglutinam processos múltiplos e complexos e se apresentam como contextos de intensas interações com os jovens. Inserido nessa conjuntura, indaga-se quais seriam as percepções dos jovens para com a cidade? Contextualizando de forma mais específica, como os jovens da cidade de Manaus, capital do estado do Amazonas, percebem sua cidade?

Essas indagações emergem não somente de uma curiosidade teórica, mas atravessa, fundamentalmente, questionamentos necessários que possam auxiliar na construção de propostas em torno de práticas socioambientais. Pensar a relação jovens-cidade tem a ver com os rumos em que se pretende dimensionar as políticas urbanas, bem como na construção e execução de projetos que vislumbrem a inserção e participação dos jovens na cidade.

\section{Contexto da pesquisa: participantes e local}

Se a pólis grega organiza-se como espaço de cidadania, embora restrita "aos seus", a cidade contemporânea situa-se como terreno das urgências ambientais e econômicas. As cidades representam $70 \%$ das emissões de gases de efeito estufa e são responsáveis pelo consumo de $75 \%$ dos recursos do mundo (ONU, 2020). Estipula-se que, em 2050, 70\% da população mundial esteja vivendo nas cidades (ONU, 2020), tendo as cidades da América Latina uma estimativa ainda mais acentuada.

As cidades contemporâneas constituem-se como a representação do modelo que preconiza o capital como paradigma econômico. É na cidade que se concentram as transações financeiras, a rede bancária, a produção fabril, a diversidade de bens e serviços que conformam e emolduram a força do sistema 
econômico vigente e a geração de riqueza (HARVEY, 2014). A cidade é o espaço da produtividade e da concentração do capital.

Manila, nas Filipinas, por exemplo, representa $47 \%$ do Produto Interno Bruto do país (ONU-HABITAT, 2016). No Brasil, essa perspectiva se torna mais relevante quando se observa que oito cidades (São Paulo - SP, Rio de Janeiro RJ, Brasília - DF, Belo Horizonte - MG, Curitiba - PR, Osasco - SP, Porto Alegre - RS e Manaus - AM) representaram 25,5\% dos bens e serviços produzidos no Brasil no ano de 2017 (IBGE, 2019).

As cidades, de fato, estão no centro das inquietações contemporâneas, principalmente, quando se observa o crescente processo de desigualdade, a degradação de áreas verdes e a geração de zonas onde a pobreza é cada vez mais presente. Com efeito, se é na cidade que se configuram os grandes desafios socioambientais, é na cidade, também, que as possibilidades de transformação social e as alternativas que envolvem tais conjunturas podem se intensificar.

Manaus reverbera tais aspectos. Sua localização incrustrada na maior floresta tropical do Mundo, a Amazônia, traz inúmeras preocupações como sua concentração econômica em detrimento as demais cidades do Estado; sua concentração demográfica, a qual representa $52,75 \%$ da população do Amazonas (IBGE, 2020) e suas inúmeras problemáticas ambientais como as queimadas urbanas e as constantes ocupações irregulares em áreas florestais. Para além desses aspectos ambientais, Manaus, historicamente constituída como um lugar de fortificação, no século XVI, representa, hoje, a fortificação do capital na região norte do país.

Com a implementação do modelo Zona Franca, por intermédio de um Polo Industrial, nos anos 60 do século passado, Manaus é o principal centro produtivo da região com suas fábricas e serviços. Esses aspectos estão diretamente vinculados ao seu crescimento populacional e sua expansão urbana nos últimos anos. A cidade que se constituiu em torno do movimento do rio Negro, espraia-se, hoje, de "costas" para esse rio "fraturando" sua fronteira urbana com a floresta, por intermédio de novas áreas residenciais, quase sempre, iniciadas por invasões e longe de qualquer planejamento habitacional (OLIVEIRA; SHOR, 2008).

Atualmente, a cidade de Manaus está distribuída em 63 bairros conformados em 6 zonas (sul, centro-sul, oeste, centro-oeste, norte e leste) (PREFEITURA MUNICIPAL DE MANAUS, 2010). Além dessa organização espacial, a cidade se conforma do encontro de diversos grupos étnicos (indígenas, quilombolas, caboclo-ribeirinhos, migrantes, por exemplo) os quais interagem e tecem inúmeras relações de convivência, de poder, e de interesses ideológicos nem sempre pautados na igualdade de acesso aos serviços ofertados pelo poder estatal. Nessa diversidade de grupos humanos, encontramse os jovens. 
De modo geral, a juventude compreende uma categoria sociológica situada entre a infância e a adultez, a qual abrange dos 15 aos 24 anos. No Brasil, o desenvolvimento de políticas públicas, segue a disposição do Estatuto da Juventude, a qual indica a juventude como sendo pessoas entre 15 e 29 anos (BRASIL, 2013), assegurando aos jovens entre 15 e 18 anos as referências legais estabelecidas no Estatuto da Criança e do Adolescente - ECA (BRASIL, 1990).

Nessa conjuntura, buscou-se identificar quais seriam as percepções dos jovens em torno da cidade de Manaus a partir de um questionário semiestruturado. Tal questionário foi aplicado para 59 jovens, no decorrer dos meses de abril a agosto de 2020. Destaca-se que todos os jovens participantes são residentes em Manaus e estudantes do ensino médio.

A utilização da percepção ambiental em compreender a cidade emerge vinculada aos seguintes componentes: estrutura, identidade e significado (LYNCH, 1982). Os estudos sobre percepções ambientais ressaltam a capacidade de as pessoas expressarem o que experimentam nos ambientes, os quais estão inseridos (MIRA, 1997; HIGUCHI; KUHNEN, 2008; 2011).

Ao se constituir como instrumento de compreensão da cidade, a percepção ambiental favorece a descrição dos elementos mais relevantes para a pessoa, permite a construção de conhecimentos acerca da realidade social dos indivíduos mediante eles mesmos, possibilita a verificação e o impacto de programas de intervenção que possam emergir das percepções das pessoas envolvidas (MIRA, 1997), bem como pode se constituir como um instrumento de subsídio de dados para construção de políticas públicas.

Assim, nesse texto, essa relação é tecida pelos jovens manauaras. Metade dos participantes, $50 \%$, indicaram seu gênero como feminino, enquanto $41,4 \%$ como masculino e $8,6 \%$ optaram em não declarar. A faixa etária mais predominante foi a de 17 anos, 55,9\%. Após a construção dos dados, sua organização e análise recebeu um tratamento qualitativo a partir da Análise de Conteúdo (BARDIN, 2016).

\section{Percepção Ambiental da Cidade}

O predomínio das cidades como lugar de habitação é uma condição contemporânea. Desse modo, a concentração populacional nos ambientes urbanos configura um outro modo de estar e existir. Habitar não se restringe ao fato de estar presente em determinado espaço, mas salvaguardar o modo como o ser humano é e estar, o qual corresponde um construir (cultivar e edificar) seu espaço (HEIDEGGER, 1954).

Destacar a percepção dos jovens sobre a cidade correlaciona uma atenção a maneira como eles constroem suas compreensões com esse contexto. Desse modo, ao observar o entendimento dos jovens sobre o ambiente verificou-se que há uma compreensão pautada no predomínio das dinâmicas naturais $(71,2 \%)$. A maior parte das respostas sinalizam a noção de ambiente 
vinculada a biodiversidade, a água, as matas, a terra/solo, ao clima e aos animais. Para a maioria dos jovens, o ambiente seria a reserva de recursos naturais.

No entanto, essa percepção, embora seja a mais expressiva, não é a única. Ela é acrescida de uma perspectiva em que o ambiente é conformado por ecossistemas naturais, onde os seres humanos estão inseridos (23,7\%). Há aqui uma integração de elementos naturais e humanos como fundamento do ambiente. Por fim, há àqueles que sinalizam o ambiente como algo criado por um ser superior $(5,1 \%)$. O ambiente é algo produzido a partir de uma transcendência e tem assento em uma visão criacionista.

Para os jovens de Manaus, a percepção sobre ambiente paira sobre três perspectivas: uma exclusivamente natural, outra que integra a dinâmica socioambiental e, por fim, uma que assenta a criação divina. Essa percepção sinaliza que a emergência das discussões ambientais, principalmente com o agravamento de sua crise nas últimas décadas, movimentou epistemologias na tentativa de compreender as bases que sustentam o fenômeno ambiental (LEFF, 2015). Uma profusão de discussões e termos (meio e eco, por exemplo) imbricaram concepções e campos teóricos distintos no intuito de forjar um conceito de ambiente complexo que articulasse processos de inúmeras ordens (física, biológica, econômica, política, cultural etc.).

O ambiente estaria vinculado com tudo aquilo que está ao lado ou ao redor de. Essa compreensão sobre a noção de ambiente agrega os fenômenos naturais e vincula-se, também, aos aparatos construídos, simbolizados e organizados pelo ser humano (CARVALHO; CAVALCANTE; NÓBREGA, 2011; LISBOA; KINDEL, 2012). Conforme se observa, entre os jovens manauaras ainda não há um entendimento pacificado de ambiente como algo integrado entre aspectos biológicos e sociais. Isso não significa, no entanto, uma percepção incorreta ou inválida, mas situa, em especial no bojo das Ciências Ambientais, a necessidade de reforçar, seja do ponto de vista teórico seja quanto suas práticas os "rumos" indicados nos últimos anos.

Se de um lado há uma visão sobre o ambiente pautada na predominância do aspecto natural, verifica-se que quando questionados se a cidade faz parte do ambiente, a noção, por outro lado, situa suas respostas não mais na mesma compreensão. Dos jovens participantes, 57,7\%, concordam com o entendimento de que cidade está inserida no ambiente. Para $23,7 \%$ há uma indecisão a respeito da afirmativa e 18,6\% indicam uma discordância em torno dela.

A noção de ambiente mais centrada nos aspectos ambientais e o reconhecimento da cidade como parte do ambiente revela uma inconsistência na compreensão em torno do que seja ambiente. Tais incompreensões necessitam transitar do domínio científico-acadêmico para outras esferas, como o ensino básico. Não se trata de um julgamento conceitual acerca de uma precisão hermética sobre 0 ambiente, mas de estimular ainda mais a 
disseminação do fazer científico e do saber ambiental junto a outros públicos, como os jovens.

A necessidade de ampliar os processos de disseminação científica nessa área traz a sua necessidade para as abordagens curriculares realizadas nos espaços formais. Os jovens participantes dessa investigação estão inseridos no ensino médio, onde existe a possibilidade de discutir, refletir e apropriar-se desses conceitos e informações, os quais podem forjar o conhecimento e visão de mundo.

Nesse sentido, a percepção ambiental é um processo de apreensão das vivências e articula basicamente a dimensão afetiva e a cognitiva (MIRA, 1997; KUHNEN, 2011). Enveredar nessa perspectiva permite o reconhecimento das condições que fomenta a crise ambiental vivenciada, uma vez que uma das medidas consideradas para superá-la é a tomada de consciência de sua gravidade pelas pessoas, através de novos hábitos, costumes, comportamentos pró-ambientais e da "leitura" dos interesses do mercado frente ao uso dos recursos naturais. Nesse ponto, os próprios jovens reconhecem, $98,3 \%$, que as pessoas estão na construção dos problemas ambientais. As pessoas estão na "base" e na "saída" da crise ambiental vivida.

Habitar a cidade, no sentido de construção e cultivo de um espaço, exige das pessoas, nesse artigo dos jovens, a contínua aprendizagem sobre como construir seu lugar no mundo (HEIDEGGER, 1954). Esse processo traz à tona uma dimensão ética, que salvaguarda valores, atitudes e sensibilidades necessárias para conservação do ambiente. Vale destacar que essa perspectiva não compreende a noção ingênua em que "cada um fazendo a sua parte" resolveria as problemáticas ambientais. Não se trata de assentar no indivíduo e em suas escolhas pessoais a responsabilidade exclusiva pelos dilemas ambientais esquecendo as incidências das políticas de estado e das grandes corporações nessa problematização. Mas, problematizar o existir nas cidades como uma alternativa aos interesses do capital, que se retira dessa discussão e indica que o comportamento das pessoas como fundamento das desordens ambientais do planeta.

Sendo assim, os dados obtidos permitem destacar a existência de um duplo movimento na percepção dos jovens em torno da cidade de Manaus. $O$ primeiro diz respeito a maneira como eles percebem a cidade quando as ações não os envolvem diretamente, isto é, quando suas percepções incidem um "olhar sobre" a compreensão da cidade. Esse movimento é concebido em algumas precariedades. O segundo, quando as percepções estão aglutinadas com a presença dos próprios jovens em determinados cenários, onde suas percepções constituem-se em padrões ambientalmente sustentável. 


\section{Manaus, a cidade do descaso para com as questões ambientais}

Quando os jovens não se sentem integrados ou responsabilizados em determinadas situações suas respostas gravitam em entendimentos revestidos de pouco apreço. Isso ocorre quando as categorias indicadas nas perguntas se revestem de uma ação que parte do outro (com que frequência você observa a preocupação da população e dirigentes com as questões ambientais da cidade?) onde os jovens não são eles próprios ou quando as categorias não incidem neles diretamente com a situação indicada (Manaus é uma cidade que se preocupa com as questões ambientais?).

Dessa forma, a população e os dirigentes, ambos com $49,2 \%$, e a própria cidade, $59,4 \%$, raramente ou nunca demonstram alguma preocupação com a temática ambiental. As respostas não induzem a um envolvimento e a um pertencimento dos respondentes na situação apresentada. É como se os jovens não se sentissem como parte integrante do ambiente citadino muito menos dos problemas produzidos nele.

O fato da preocupação não está associado a si mesmo, as carências e precariedades reveladas são indicadas como responsabilidades de outros e a sua relação com o ambiente parece não constituir vínculo algum. Ora, se não há um reconhecimento como parte do ambiente no qual está inserido, não ocorre uma relação de envolvimento e apreço para com ele (TUAN, 2012), sendo, portanto, a cidade uma preocupação e responsabilidade dos outros e não de si, nesse caso, dos jovens.

Nessa conjuntura, a sensação percebida em torno das questões ambientais na cidade de Manaus elucida um afeto desagradável marcado pela agitação e indiferença para $94,9 \%$. Os demais, $5,1 \%$, indicam uma reação pautada em uma condição agradável e tranquila. Por seu turno, quando expressam a palavra que mais representam seu pensamento em torno das questões ambientais de Manaus os termos menos apreciativos foram os mais salientes (Figura 1).

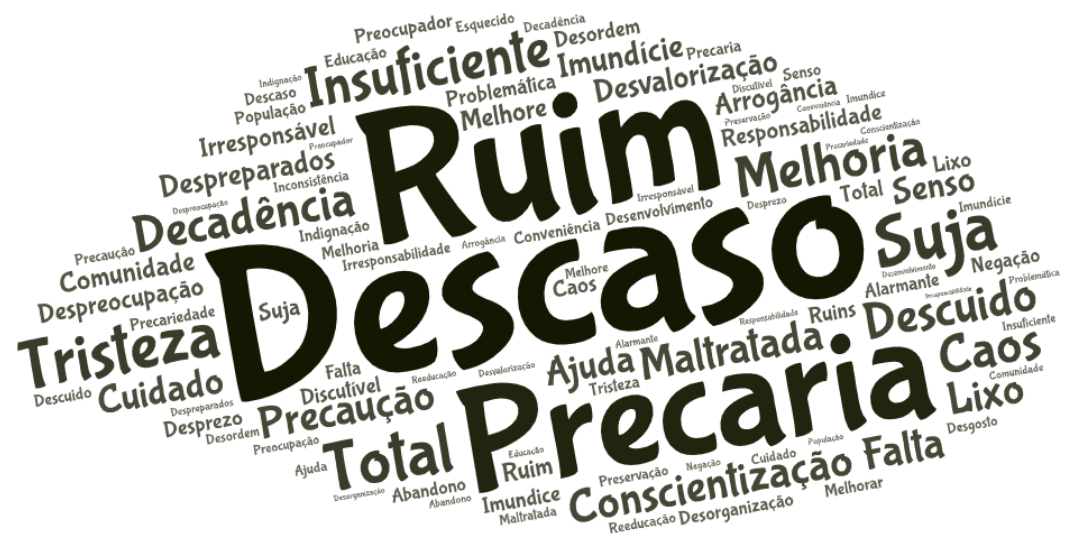

Figura 1: nuvem de palavras

Fonte: o autor, 2020.

Revbea, São Paulo, V.16, № 5: 233-246, 2021.

revista brasileira

educação ambiental 
Essa construção perceptual reverbera contextos constituídos por diversas experiências que expressam sentidos e significados. A percepção apresentada pelos jovens é construída por influências e atravessamentos no bojo da cidade, principalmente àquelas que produzem e reproduzem a engrenagem do capital. "A cidade é expressão das relações sociais de produção capitalista, sua materialização política e espacial [...]” (IASI, 2013, p. 41).

Como uma unidade forjada por vários elementos, por vezes contrárias em si, a cidade apresenta modos de vivência baseada em casulos individuais, isto é, seus habitantes se presentificam em espaços comuns, participam de conjunturas grupais, mas não formam e nem se identificam com um grupo. A cidade produz um coletivo serial nas relações cotidianas, onde prevalece um "olhar" fragmentado, desarticulado e indiferente (IASI, 2013).

Reconhecer essa percepção aglutina o fato de que o processo de globalização e a ênfase neoliberal constituiu cidades divididas e estilhaçadas sob a égide da desigualdade (HARVEY, 2013). A cidade compreendida na expressão do contemporâneo reverbera características próprias desse momento, onde a produção urbana se vincula a um modo de existir impregnado pelas condições do empresariamento (ALVES; RIZEK, 2014). As novas formas de consumo interpõem detrimento da lógica da vida púbica, da cidadania e dos direitos humanos diante de concepções mercantis que ressaltam o empreendedorismo de si.

A lógica dessa conjuntura busca instaurar um modo de regular a cidade pela privatização dos espaços, das relações de poder, do controle administrativo e da moralidade, onde tais aspectos são constituídos, quase sempre, pelos que detém o controle dos meios de produção. A referência é uma cidade cada vez mais esvaziada em seu ordenamento público, a qual teria como objetivo consagrar o acesso aos bens, serviços e direitos para todos.

Essa privatização do estar na cidade é forjada em coletivos empresariais/institucionais, que utilizam e produzem discursos que salientam a individualização das responsabilidades de cada um no habitar com o intuito de enfraquecer a própria teia coletiva e salvaguardar, assim, seus interesses (ALVES; RIZEK, 2014). O direito à cidade parece se constituir em uma feitura formal, mas não prática. Formal quanto a sua estrutura e o ordenamento regulador das responsabilidades. Mas, efetivamente distante porque 0 pertencimento, o envolvimento e inclusão de todos numa construção social equitativa fica restrito a alguns poucos.

Esse cenário fica explicito na percepção juvenil identificada e se materializa quando se verifica que nas áreas territoriais da cidade de Manaus as discrepâncias da oferta dos serviços públicos são salientes. Somente um exemplo para ilustrar tal situação, do ponto de vista das ações de políticas públicas no âmbito cultural (área onde a presença dos jovens, em tese, deveria ser bem expressiva), observa-se que há uma concentração de equipamentos culturais (museus e teatros, por exemplo) e eventos no centro histórico da cidade. Tais espaços foram construídos e produzidos para "resgatar" a 
exuberância dos tempos áureos da borracha, onde a cidade de Manaus era tida como a "Paris dos Trópicos". Em contrapartida, em outras áreas, principalmente na zona norte e leste, onde a efervescência do processo de urbanização está em pleno vigor, há alguns poucos espaços e incentivos para construção e fomento de manifestações artístico-culturais.

O não envolvimento e por sua vez o não reconhecimento de si em situações que coadunam o cotidiano reflete não uma posição de indiferença ou egocêntrica dos jovens para com a cidade. Mas, uma condição das cidades contemporâneas onde a quantidade de informações e configurações centradas da ética da individualização distanciam as aspirações e as ações das pessoas no cotidiano. Essa condição dificulta a construção de fios que tendem tecer a apropriação do seu meio (POL, 1996).

A compreensão em torno da cidade identifica-se, assim, com construções serializadas que "silenciam" o estar do jovem em determinado contexto. Do ponto de vista da relação pessoa-ambiente há a necessidade de fortalecer os vínculos que forjam a identificação e/ou o pertencimento dos jovens para com o seu entorno, isto é, processo de apropriação precisa se constituir. Não é possível criar vínculo se não há pertencimento para com o espaço habitado.

Esse processo de apropriação é essencialmente mediado pelas expectativas emocionais e pessoais. Como um processo psicossocial, mostrase como uma possibilidade da pessoa de se sentir parte e de ter domínio de um espaço, com vista a sua inserção e atuação. Pode-se dizer, que a apropriação é a inscrição existencial da pessoa em um lugar, o qual passa a ser considerado relevante e demanda um vínculo ou enraizamento no mesmo (MOURÃO; CAVALCANTE, 2006).

Assim, se os jovens não percebem e não reconhecem a necessidade de engajamento ou atuação em determinado contexto, esse não é apropriado e não se constitui em sua relação. Como a ação e o sentimento estão interligados nesse processo, a construção de sentidos e pertencimento prescindem desses aspectos. Dessa forma, o espaço não reconhecido só se torna preenchido e recíproco quando a pessoa percebe a sua integração no mesmo.

\section{Manaus, uma cidade potencialmente sustentável}

Vive-se constituído em um contexto. A relação da pessoa com 0 ambiente é uma condição inevitável. No entanto, o modo de interação depende de fatores sociais, subjetivos, materiais e simbólicos. Observou-se que o envolvimento direto dos jovens produz e constrói maneiras distintas de configurar tal percepção. Desse modo, o reconhecimento de si nos contextos evidencia uma outra maneira de perceber a cidade.

De uma cidade do descaso, Manaus é compreendida como uma cidade potencialmente sustentável. O que influencia tal mudança? O envolvimento e 0 
reconhecimento de si no cenário discutido têm a ver com familiaridade construída nessa interface, momento em que a apropriação se constrói e se efetiva (FISCHER, 1994), ou seja, a apropriação é "um processo essencial para que alguém se sinta identificado ou pertencente a um entorno" (MOURÃO; CAVALCANTE, 2006, p. 145).

Essa identificação é salientada, principalmente, quando são indagados a respeito de suas contribuições para a mitigação dos problemas ambientais enfrentados pela cidade. A maioria, $83,1 \%$, destaca que contribuiria para minimizar os impactos provocados no meio ambiente. Outros, $13,6 \%$, destacam que fariam algo, desde que fossem provocados e $3,4 \%$ sinalizam que estariam dispostos a contribuir com algo, mas ressaltam que essa não é responsabilidade deles.

Essa perspectiva, reforça a compreensão de que os jovens precisam estar integrados ou mesmo serem mobilizados para participar dos processos que envolvem a cidade. Quando estão inseridos e envoltos da situação citadina há uma aproximação e um reconhecimento de suas demandas tanto do ponto de vista do conhecimento quanto do seu envolvimento afetivo.

É nesse sentido, que os problemas ambientais da cidade se constituem como desafios que podem ser problematizados pela juventude em Manaus. Os jovens conseguem identificar, reconhecer e nominar as problemáticas ambientais, como o desmatamento, as queimadas, a poluição do ar por conta das empresas, a destinação dos resíduos sólidos, as invasões de terra e a conservação dos recursos hídricos. Em tais contextos, os jovens indicam que eles podem colaborar e atuar.

Ao intencionar o envolvimento com tais questões, os jovens conseguem identificar uma Manaus com potencialidades ambientais que podem inspirar ações e modos mais sustentáveis, como a iluminação elétrica da cidade, que recentemente substituiu os modelos fluorescentes pelas de $L E D$, o incentivo de projetos e programas de arborização, bem como conservação de parques e áreas verdes e, por fim, a expansão na rede de distribuição de água encanada. Esses elementos emergem como características de uma cidade que se organiza mediante ações sustentáveis.

Outro momento em que se percebe um envolvimento com a cidade, na percepção dos jovens, é quando a convivência com a cidade se pauta pelas condições econômicas e de consumo. Quando indagados se estariam dispostos a conviver com uma cidade com problemas ambientais caso isso thes trouxessem mais retorno financeiro, a maioria respondeu que não, 54,2\%. E ainda, se estariam dispostos a pagar mais caro por um produto que causasse menos dano ao ambiente da cidade, majoritariamente, $74,6 \%$, indicaram que $\operatorname{sim}$.

É interessante observar que nos padrões econômico e de consumo há uma sinalização do comprometimento dos jovens para com a cidade. A apropriação desse aspecto pelos jovens reverbera 0 entendimento da 
sustentabilidade como possibilidade reapropriação dos recursos produzidos em contexto com uma racionalidade ambiental que promova a lógica da responsabilização pelo ambiente vivido pelos jovens e pelas corporações do capital.

Os jovens indicam que além da dimensão natural da cidade, em que se destaca a preservação do ambiente, há um indicador relevante na percepção de uma cidade potencialmente sustentável que diz respeito a consciência em torno do consumo de seus habitantes. Conservar a floresta, os rios, os igarapés são elementos imprescindíveis. Essa compreensão torna-se, ainda mais saliente, quando o consumo intermedia essa consciência. Conservar os elementos naturais é uma finalidade que perpassa pelos hábitos de adquirir e consumir algo, bem como da maneira como o empresariamento extrai e apresenta seus produtos.

Essa perspectiva salienta um modo de apropriação baseada na açãotransformação (POL, 1996). Como componente primário do estar das pessoas no ambiente. Suas ações e suas interações estão envolvidas em processos dinâmicos e temporais, nos quais podem intervir e alterá-los. Aqui não é algo instintivo de proteção em torno do meio inserido, mas de intencionalidade em agir sobre o ambiente, isto é, as formas de consumo, forjadas no âmbito pessoal, podem modificar as relações estabelecidas com as questões ambientais.

A participação das pessoas está diretamente vinculada ao processo de apropriação. Essa perspectiva é fundamental para a noção de sustentabilidade. $\mathrm{O}$ fortalecimento do tecido social pelo envolvimento das pessoas para com o contexto no qual está inserido confere a sustentabilidade como um campo de ressignificação das relações socioambientais. Esse aspecto destaca, fundamentalmente, a compreensão necessária para tornar as cidades e os assentamentos humanos inclusivos, seguros, resilientes e sustentáveis (ONU, 2015).

A participação das pessoas evidencia um exercício da cidadania, que traz a esfera pública como uma alternativa as desigualdades e segregações urbanas (MORANTA; URRÚTIA, 2005). Sendo assim, a aproximação entre os jovens e a cidade é mediada diretamente pela sua participação. O conhecimento e reconhecimento dos elementos conformam e produzem as relações urbanas interpõem um grau de pertencimento e envolvimento que ocorre à medida em que os jovens identificam suas atividades na pólis. Em outras palavras, se enquanto pessoas se sentem atuantes.

Assim, as informações, os diálogos, os afetos, os sentimentos produzidos e construídos na interface da cidade perpassam pela presença ativa dos jovens. Se a cidade contemporânea conflui para entendimentos seriados e individualizantes, a percepção dos jovens é de uma cidade também fragmentada e dissonante. Por outro lado, se os jovens participam e se sentem envolvidos, a percepção da cidade se espraia pelas suas potencialidades e emergem pela apropriação um terreno para sustentabilidade. 


\section{Conclusões}

Os estudos de percepção ambiental colaboram na compreensão das interrelações da pessoa com o ambiente no qual estão inseridos. A construção da percepção dos jovens em torno da cidade de Manaus evidencia que não é suficiente estar na cidade, circular por ela ou experimentar a diversidade de espaços que a constituem. A construção perceptual evidencia que o processo de apropriação a cidade e, consequentemente, o modo como ela é entendida está vinculada com maneira dos jovens participarem de seus processos.

Os afetos construídos, as identificações realizadas, as trocas de experiências atravessam o processo de percepção em torno da cidade. No entanto, as valências mais positivas ou negativas vinculam diretamente com o participar, o envolver, o reconhecer-se nos contextos salientados. Nota-se a urgência da construção de elementos e processos que oportunizem a participação e envolvimento dos cidadãos (dos jovens) para com a cidade.

Os discursos de indiferença e não envolvimento propagados no domínio social perpetram compreensões fragmentadas e isoladas da realidade. Essa construção possui interesse e intencionalidade: despolitizar a ação da pessoa e sobrepor modos e maneiras de agir que respondam aos interesses produtivos. A massa de consumidores e não de cidadãos é o que se almeja. Para tanto, a regulação de uma cidade sob a ótica da produção e da privatização ressalta uma individualização das práticas e dos processos simbólicos que abocanha 0 público pela indiferença.

Desse modo, as percepções vislumbradas, de uma cidade do descaso a uma cidade potencialmente sustentável estão vinculadas para além das dimensões físicas e suas relevâncias na composição dos aspectos ambientais, mas na maneira dos jovens se sentirem pertencentes as mesmas. A centralidade da relação jovens-cidades baseia-se no encontro das experiências e no exercício de cidadania. Essa condição indica que a cidade, como melhor expressão e refinamento do capitalismo, é a construção empírica de outras lógicas de atuação sobre o espaço e, consequentemente, de percepção.

Assim, o direito à cidade é uma mobilização de envolvimento e engajamento sobretudo nas ocupações e significados dados ao ambiente. $O$ quanto se envolve, se preocupa, se deixa afetar constitui parâmetros para cuidar, preservar e conservar a cidade. Afinal, se não ocorrer a compreensão do ambiente como elemento integrante da condição humana o estar na cidade não é suficiente para salvaguardar nosso lugar comum.

\section{Referências}

ALVES, M.R.; RISEK, C.S. Cidade Contemporânea, Cidade do Empresariamento: aspectos da produção socioespacial do urbano. In.: RODRIGUEZ, J.E.B. et al. (orgs.). Os Estudos Socioespaciais: cidades, fronteiras e mobilidade humana. Manaus: Editora da Universidade Federal do Amazonas, 2014. 
BARDIN, L. Análise de Conteúdo. São Paulo: Edições 70, 2016.

BRASIL. Lei NN.9 8.069, 13 de julho de 1990. Dispõe sobre o Estatuto da Criança e do Adolescente e dá outras providências. Disponível em: <http:// www.planalto.gov.br/ccivil 03/leis/L8069.htm>. Acessado em 14/09/2020.

BRASIL. Lei N.-12.852, de 5 de agosto de 2013. Institui o Estatuto da Juventude e dispõe sobre os direitos dos jovens, os princípios e diretrizes das políticas públicas de juventude e o Sistema Nacional de Juventude - SINAJUVE. Disponível em <http://www.planalto.gov.br/ccivil 03/ Ato20112014/2013/Lei/L12852.htm>. Acessado no dia 14 de setembro de 2020.

CARVALHO, M.I.C.; CAVALCANTE, S.; NÓBREGA, L.M.A. Ambiente. In: Temas básicos em Psicologia Ambiental. Rio de janeiro: Vozes, 2011.

FISCHER, G.N. Psicologia social do ambiente. Lisboa: Instituto Piaget, 1994.

HARVEY, D.A Liberdade da cidade. In.: Cidades Rebeldes: passe livre e as manifestações que tomaram as ruas do Brasil. 1.ed. São Paulo: Boitempo: Carta Maior, 2013.

HARVEY, D. Cidades Rebeldes: do direito à cidade à revolução urbana. São Paulo: Martins Fontes, 2014.

HEIDEGGER, M. Construir, Habitar, Pensar. Conferência pronunciada por ocasião da "Segunda Reunião de Darmastad", publicada em Vortäge und Aufsätze, G. Neske, Pfullingen, 1954. Tradução de Marcia Sá Cavalcante Schuback. Disponível em <https://www.fau.usp.br/wp-content/uploads/2016/12/ heidegger construir habitar pensar.pdf>. Acessado em 28 de agosto de 2020.

HIGUCHI, M.I.G.; KUHNEN, A. Percepção e Representação Ambiental: métodos e técnicas de investigação para a Educação Ambiental. In: PINHEIRO, J.Q.; GÜNTHER, H. Métodos de pesquisa nos estudos pessoa-ambiente. São Paulo: Casa do Psicólogo, 2008.

HIGUCHI, M.I.G.; KUHNEN, A. Percepção Ambiental. In: CAVALCANTE, S.; ELALI, G.A. (orgs.). Temas básicos em Psicologia Ambiental. Petrópolis: RJ: Vozes, 2011.

IASI, M.L. A rebelião, a cidade e a consciência. In.: Cidades Rebeldes: passe livre e as manifestações que tomaram as ruas do Brasil. 1.ed. São Paulo: Boitempo: Carta Maior, 2013.

INSTITUTO BRASILEIRO DE GEOGRAFIA E ESTATÍSTICA - IBGE. Estimativas da População, 2020. Disponível em $<$ https://www.ibge.gov.br/estatisticas/sociais/populacao/9103-estimativas-depopulacao.html?=\&t=resultados $>$. Acessado no dia 14 de setembro se 2020.

INSTITUTO BRASILEIRO DE GEOGRAFIA E ESTATÍSTICA - IBGE. Produto Interno Bruto dos Municípios, 2017. Rio de Janeiro: IBGE, 2019.

KUHNEN, A. Percepção Ambiental. In: CAVALCANTE, S.; ELALI, G.A. (orgs.). Temas básicos em Psicologia Ambiental. Petrópolis: RJ: Vozes, 2011. 
LEFF, E. Saber Ambiental: sustentabilidade, racionalidade, complexidade, poder. Petrópolis/RJ: Vozes, 2015.

LISBOA, C.P.; KINDEL, E.A.I.(org.). Educação Ambiental: da teoria à prática. Porto Alegre: Mediações, 2012.

MIRA, R.G. La ciudad percebida: una psicología ambiental de los bairros de a Coruña. Coruña: Universidade da Coruña, 1997.

MORANTA, T.V.; URRÚTIA. E.P. La apropiación del espacio: una propuesta teórica para comprender la vinculación entre las personas y los lugares. Anuario de Psicología, Barcelona, vol. 36, n. 3, p. 281-297, 2005.

MOURÃO, A.R.T.; CAVALCANTE, S. O processo de construção do lugar e da identidade dos moradores de uma cidade reinventada. Estudos de Psicologia, 11(2), p.143-151, 2006.

OLIVEIRA, J.A.; SHOR, T. Manaus: transformações e permanências do forte à metrópole regional. In.: CASTRO, E. (Org.). Cidades na Floresta. São Paulo: Annablume, 2008.

ORGANIZAÇÃO DAS NAÇÕES UNIDAS - ONU Transformando Nosso Mundo: A Agenda 2030 para o Desenvolvimento Sustentável, 2015. Disponível em: <https://nacoesunidas.org/wp-content/uploads/2015/10/ agenda2030-pt-br.pdf>. Acesso em: 27 de setembro de 2017.

ORGANIZAÇÃO DAS NAÇÕES UNIDAS - ONU-HABITAT. Urbanization and Development: emerging futures. Nairobi, Kenya, 2016. Disponível em $<$ http://cdn.plataformaurbana.cl/wp-content/uploads/2016/06/wcr-full-report2016.pdf >. Acesso em: 14 de setembro de 2020.

ORGANIZAÇÃO DAS NAÇÕES UNIDAS - ONU. Fórum global sobre cidades destaca desenvolvimento sustentável, 12 de fevereiro de 2020. Disponível em $<$ https://www.unenvironment.org/pt-br/noticias-ereportagens/reportagem/forum-global-sobre-cidades-destaca-desenvolvimentosustentavel>. Acessado no dia 14 de setembro de 2020.

PAZ, D.T. Aspectos constitutivos do engajamento e participação de jovens em coletivos socioambientais na região metropolitana de Manaus/AM. $78 \mathrm{f}$. Dissertação (Mestrado em Ciências do Ambiente e Sustentabilidade na Amazônia) - Universidade Federal do Amazonas, Manaus, 2017.

POL, E. La apropiación del espacio. In: IÑIGUEZ, L.; POL, E. (orgs.). Cognición, representación y apropiación del espacio. Barcelona: Universitat de Barcelona, 1996.

PREFEITURA MUNICIPAL DE MANAUS. Lei № 1.401, de 14 de janeiro de 2010. Dispõe sobre a criação e a divisão dos bairros da cidade de Manaus, com estabelecimento de novos limites. Disponível em $<$ http://dom.manaus.am.gov.br/ pdf/2010/janeiro/dom2365cad1.pdf>. Acessado no dia 14 de setembro de 2020.

TUAN, Yi-Fu. Topofilia: um estudo da percepção, atitudes e valores do meio ambiente. Londrina: Eduel, 2012. 